\title{
Community use of naloxone for opioid overdose
}

\section{SUMMARY}

Naloxone is a competitive antagonist at opioid receptors. It can be administered to reverse the effects of an opioid overdose.

In the face of increasing overdose deaths, from both prescription opioids and heroin, a wide range of people may benefit from increased access to naloxone. It has now been made available on the Pharmaceutical Benefits Scheme and over-the-counter from pharmacies.

After brief training, numerous evaluation studies have confirmed naloxone can be safely administered by laypeople, and is effective in reversing opioid overdose with no abuse potential.

Health professionals are uniquely placed to identify those at risk of opioid toxicity and provide them with a life-saving drug. Training can also be offered to the family and friends of the person at risk of overdose.

\section{Introduction}

Accidental opioid overdose continues to increase in Australia, now contributing to an average of 1.5 deaths daily. 'While heroin (diacetylmorphine) may receive more media attention, prescription opioids are now responsible for more overdose deaths. There is therefore a broad and growing population affected by, and at risk of, opioid overdose. Importantly, opioid overdose deaths are preventable.

In the USA, an opioid overdose epidemic has seen a trebling in opioid-related mortality in recent years. In response, expanding the distribution of the opioid antagonist naloxone has been widely recommended..$^{2-4}$ Naloxone reverses potentially fatal respiratory depression. Over 18 years, up until 2014, there were approximately 152000 naloxone kits distributed or prescribed, and over 26000 successful reversals of overdose were reported. ${ }^{5}$

In Australia the first community distribution program began in the Australian Capital Territory in $2011 .{ }^{6}$ There are now small naloxone programs in many areas. Most were established through peer and consumer organisations or drug and alcohol services, but naloxone has not been widely available. On 1 February 2016 naloxone became available as a Schedule 3 medicine. This means it is now available as an over-the-counter drug without prescription, as well as on prescription and subsidised through the Pharmaceutical Benefits Scheme (PBS).

\section{Pharmacology}

Naloxone is a competitive antagonist at opioid receptors. It has a fast onset of action and short half-life. When administered in the presence of an opioid, naloxone displaces the opioid at the receptor and thus reverses its effects - most importantly it reverses the respiratory depression which causes death. This works for all opioid drugs, such as heroin, oxycodone and morphine. When given intramuscularly naloxone takes a few minutes to start working and its effects last for about an hour. It is approved in Australia for intramuscular, intravenous and subcutaneous use and has been successfully used by ambulance and paramedical staff for the treatment of opioid overdose for over 40 years.

The concept behind broader availability of naloxone, or 'take-home naloxone,' is that this drug has very few adverse effects, has no abuse potential, and is very effective at reversing the effects of opioids. ${ }^{7}$ When given to healthy volunteers with no recent opioid exposure, it has no clinical effect. ${ }^{8}$ If naloxone is given to someone who is unresponsive for a reason other than opioid toxicity, naloxone is extremely unlikely to cause harm. The greatest risk is transient opioid withdrawal symptoms in someone who is opioid dependent. However, these are uncommon when starting doses of 400-800 micrograms are used.

\section{Community supply}

Most deaths from overdose occur in the presence of another person. In relation to overdoses involving illicit drugs, there may be a reticence to call an ambulance because of fear of police involvement. Broader availability of naloxone among those using and injecting illicit drugs and their friends and family can be life-saving.

\section{Marianne E Jauncey \\ Medical director \\ Conjoint senior lecturer ${ }^{2}$ \\ Clinical senior lecturer ${ }^{3}$ \\ Suzanne Nielsen \\ Senior research fellow ${ }^{2}$ \\ Pharmacist ${ }^{4}$ \\ 'Uniting Medically \\ Supervised Injecting Centre \\ ${ }^{2}$ National Drug and Alcohol Centre \\ University of New South Wales \\ 3 Sydney Medical School University of Sydney \\ ${ }^{4}$ Drug and Alcohol Services South Eastern Sydney Local Health District \\ Sydney}

\section{Keywords}

drug overdose, naloxone, narcotic antagonists, opioids

Aust Prescr 2017:40:137-40 https://doi.org/10.18773/ austprescr.2017.043

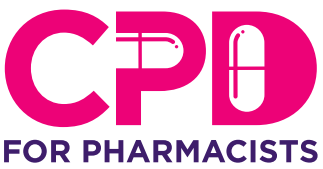

This article has a continuing professional development activity for pharmacists available at

https://learn.nps.org.au 
Around half of the overdoses of prescription opioids involve patients with chronic pain. These patients often have little understanding of the risks of overdose, especially the risks associated with the concomitant use of central nervous system depressants, such as alcohol and benzodiazepines. They and their friends and families need training and it is essential for GPs and pharmacists to facilitate this. Training must include highlighting the risks of overdose and how best to intervene. For this group of patients access to naloxone presents a very good opportunity for early, pre-hospital intervention. Preliminary research in Australia indicates that most chronic pain patients prescribed opioids would either expect to be offered naloxone or would appreciate it. ${ }^{9}$ There is therefore a role and an opportunity to consider naloxone supply in a range of populations at risk of opioid overdose. ${ }^{10}$

The feasibility of a take-home naloxone supply has been demonstrated in Sydney with 30 successful overdose reversals reported in a trial of 83 participants." This is in addition to numerous international studies that have shown that supplying naloxone for layperson administration is safe, feasible and cost-effective. ${ }^{12-16}$ The World Health Organization now recommends naloxone as a strategy to reduce overdose deaths. ${ }^{17}$

Among GPs and pharmacists, experience with naloxone may be limited, but there is strong support from pharmacists for overdose prevention and naloxone supply. ${ }^{18}$ GPs and pharmacists are uniquely placed to engage with high-risk individuals and their friends and families. It is essential that health professionals are supported to better identify which patients need naloxone, and to train these patients appropriately.

The wider provision of take-home naloxone with overdose training means that a life-saving drug may be immediately available in the place an overdose occurs. Anyone may purchase naloxone over-thecounter, regardless of their own personal risk of overdose. Naloxone may also be prescribed to anyone at risk of overdose, and provided at reduced cost through the PBS.

\section{Training}

Research shows that laypeople can be trained in 5-10 minutes to appropriately identify an overdose, and intervene. This includes the administration of naloxone. ${ }^{19}$ While longer and more detailed training should be available when requested, and could include CPR, evidence shows that brief intervention is effective ${ }^{19}$ and may facilitate uptake, whereas longer training may prove a disincentive. Key steps involve positioning the patient to enable breathing, rescue breaths if willing and able, and naloxone injection into the thigh or deltoid (see Box). The training should emphasise the importance of calling an ambulance because sometimes the duration of action of the opioid will exceed that of naloxone. Subsequent doses of naloxone or ongoing medical supervision may be required.

A simple one-page document highlighting important points and summarising the training should be provided. Training resources as well as further background information are available at http://creidu.edu.au/naloxone and www.copeaustralia.com.au/resources.

\section{Who should have naloxone?}

Any person at risk of an opioid overdose, or those likely to be present at an opioid overdose, should be considered for training. This includes patients on prescribed opioids, particularly those with risk factors for opioid toxicity. It includes anyone using illicit opioid drugs, especially those attending detoxification and rehabilitation services, but also patients taking opioid substitution therapy like methadone and buprenorphine. Regardless of whether opioid use is licit or illicit, anyone at risk of opioid overdose should be considered for naloxone.

The greatest risk of overdose death is when there is a reduced or absent tolerance to opioids. This is often seen after a period of reduced use such as following detoxification or prison. The risk is also high when opioids are taken with other central nervous system depressants, notably alcohol and benzodiazepines. These key risk factors are important to include in any brief training.

\section{Box Key training information for the use of naloxone}

Signs of overdose include:

- reduced respiratory rate and depth (that is, not breathing or snoring deeply and turning blue)

- reduced responsiveness, unconsciousness (that is, you cannot wake them up)

- small or pinpoint pupils.

When opioid overdose is suspected:

- position the person to open their airway

- give a few quick mouth-to-mouth breaths if willing and able

- call an ambulance and immediately give an intramuscular dose of naloxone 400 micrograms (in thigh or deltoid)

- continue rescue breathing, and repeat naloxone 400 micrograms every 2-3 minutes until the person begins to wake up 


\section{Naloxone supply}

Naloxone is available in Australia in prefilled syringes or ampoules. The current prefilled syringe product is known as Prenoxad and contains $2 \mathrm{mg}$ (five 400 microgram doses in a single-use syringe). Importantly this product already contains a needle tip for administration. Ampoules each contain 400 micrograms, and a $3 \mathrm{~mL}$ syringe and a $23 \mathrm{~g}$ needle are needed to allow administration. Needles can be purchased or may be available through programs that supply clean injecting equipment. Additional materials may be considered, such as skin wipes, gloves and a face mask for rescue breathing. There is no limit to the quantity of naloxone that may be provided. A supply of multiple doses is recommended as a single dose may not be sufficient to reverse an overdose. Ideally a minimum of two 400 microgram doses should be provided to allow for repeat dosing, or the possibility of a broken ampoule. A PBS prescription enables the supply of five 400 microgram ampoules, or one prefilled and singleuse syringe with five 400 microgram doses.

\section{Common myths and misconceptions}

Reviews have found that expanding the provision of naloxone is not associated with greater risk-taking by patients or any increase in drug use. Another review of two studies that specifically examined opioid use among those who trained with naloxone found a reduction in drug use. ${ }^{20}$

Naloxone will work even with more potent opioids, such as fentanyl. While higher doses of naloxone may be required, a fentanyl overdose can be reversed with naloxone.
Buprenorphine has a particularly high affinity at the opioid receptor site so may also require higher doses of naloxone to reverse its effects. ${ }^{21,22}$

Another source of concern is that the recipient will awaken with acute withdrawal and display aggression. Australian experience suggests this problem is uncommon, especially when starting with doses of 400-800 micrograms. ${ }^{6,11}$

\section{Conclusion}

Deaths from accidental opioid overdose can be prevented by naloxone. Australian healthcare providers need to identify patients at risk of opioid overdose and be actively involved in the provision of brief training and facilitation of naloxone supply. This should involve greater over-the-counter availability as well as increasing prescriptions. A minimum of two 400 microgram naloxone doses along with needles and $3 \mathrm{~mL}$ syringes (for ampoules) should be provided, in addition to training. Evidence suggests this can safely and effectively reduce overdose deaths. $<$

Marianne Jauncey is the Medical Director of the Uniting Medically Supervised Injecting Centre where she runs a naloxone distribution program for clients of the service.

Suzanne Nielsen is supported by a National Health and Medical Research Council Research Fellowship (1013803). The National Drug and Alcohol Research Centre at the University of New South Wales is supported by funding from the Australian Government under the Substance Misuse Prevention and Service Improvements Grant Fund.

Suzanne Nielsen has been an investigator on untied educational grants from Reckitt-Benckiser and Indivior.

\section{REFERENCES}

1. Roxburgh A, Burns L. Accidental drug-induced deaths due to opioids in Australia. Sydney: National Drug and Alcohol Research Centre, UNSW; 2012. https://ndarc.med.unsw.edu. au/resource/accidental-drug-induced-deaths-due-opioidsaustralia-2012 [cited $2017 \mathrm{Jul} 1$ ]

2. Rudd RA, Aleshire N, Zibbell JE, Gladden RM. Increases in drug and opioid overdose deaths - United States, 20002014. MMWR Morb Mortal Wkly Rep 2016:64:1378-82. https://doi.org/10.15585/mmwr.mm6450a3

3. Straus MM, Ghitza UE, Tai B. Preventing deaths from rising opioid overdose in the US - the promise of naloxone antidote in community-based naloxone take-home programs. Subst Abuse Rehabil 2013;4:65-72. https://doi.org/ 10.2147/SAR.S47463

4. Murthy V. Our addiction crisis can be solved - with hard work. Time Magazine 2016;188:53. www.scribd.com/ article/327612101/Our-Addiction-Crisis-Can-Be-Solved-WithHardwork [cited 2017 Jul 1]

5. Centers for Disease Control and Prevention. Opioid overdose prevention programs providing naloxone to laypersons - United States, 2014. MMWR Morb Mortal Wkly Rep 2015;64:631-5.
6. Olsen A, McDonald D, Lenton S, Dietze P. Independent evaluation of the 'Implementing Expanded Naloxone Availability in the ACT (I-ENAACT)' program, 2011-2014. Final Report. ACT Health: Canberra; 2015. https://health. act.gov.au/sites/default/files//Naloxone\%20Evaluation\%20 Report\%20FINAL_August\%202015.pdf [cited 2017 Jul 1]

7. McDonald R, Strang J. Are take-home naloxone programmes effective? Systematic review utilizing application of the Bradford Hill criteria. Addiction 2016;111:1177-87. https://doi.org/10.1111/add.13326

8. Foldes FF. The human pharmacology and clinical use of narcotic antagonists. Med Clin North Am 1964;48:421-43.

9. Nielsen S, Peacock A, Lintzeris N, Bruno R, Larance B, Degenhardt L. Overdose knowledge and perceptions of takehome naloxone for patients with chronic non-cancer pain. Paper 84. Australasian Professional Society on Alcohol and other Drugs Conference 2016, Sydney, Australia, 30 October-2 November 2016. Drug Alcohol Rev 2016;35 Suppl 1:4-76. https://doi.org/10.1111/dar.12484

10. Oliva EM, Nevedal A, Lewis ET, McCaa MD, Cochran MF, Konicki PE, et al. Patient perspectives on an opioid overdose education and naloxone distribution program in the U.S. Department of Veterans Affairs. Subst Abus 2016;37:118-26. https://doi.org/10.1080/08897077.2015.1129528 
<ustralian Prescriber

11. Chronister KJ, Lintzeris N, Jackson A, Ivan M, Dietze P, Lenton S, et al. Findings and lessons learnt from implementing Australia's first health service based takehome naloxone program. Drug Alcohol Rev 2016 Apr 13. https://doi.org/10.1111/dar.12400

12. Clark AK, Wilder CM, Winstanley EL. A systematic review of community opioid overdose prevention and naloxone distribution programs. J Addict Med 2014;8:153-63. https://doi.org/10.1097/ADM.0000000000000034

13. Coffin PO, Sullivan SD. Cost-effectiveness of distributing naloxone to heroin users for lay overdose reversal. Ann Intern Med 2013;158:1-9. https://doi.org/10.7326/ 0003-4819-158-1-201301010-00003

14. Giglio RE, Li G, DiMaggio CJ. Effectiveness of bystander naloxone administration and overdose education programs: a meta-analysis. Inj Epidemiol 2015;2:10. https://doi.org/ 10.1186/s40621-015-0041-8

15. Bennett AS, Bell A, Tomedi L, Hulsey EG, Kral AH. Characteristics of an overdose prevention, response, and naloxone distribution program in Pittsburgh and Allegheny County, Pennsylvania. J Urban Health 2011;88:1020-30. https://doi.org/10.1007/s11524-011-9600-7

16. Walley AY, Xuan Z, Hackman HH, Quinn E, Doe-Simkins M, Sorensen-Alawad $A$, et al. Opioid overdose rates and implementation of overdose education and nasal naloxone distribution in Massachusetts: interrupted time series analysis. BMJ 2013;346:f174. https://doi.org/10.1136/bmj.f174
17. World Health Organization. Community management of opioid overdose. Geneva: World Health Organization; 2014.

18. Nielsen S, Menon N, Larney S, Farrell M, Degenhardt L. Community pharmacist knowledge, attitudes and confidence regarding naloxone for overdose reversal. Addiction 2016;111:2177-86. https://doi.org/10.1111/add.13517

19. Behar E, Santos GM, Wheeler E, Rowe C, Coffin PO. Brief overdose education is sufficient for naloxone distribution to opioid users. Drug Alcohol Depend 2015;148:209-12. https://doi.org/10.1016/j.drugalcdep.2014.12.009

20. Bazazi AR, Zaller ND, Fu JJ, Rich JD. Preventing opiate overdose deaths: examining objections to take-home naloxone. J Health Care Poor Underserved 2010;21:1108-13. https://doi.org/10.1353/hpu.2010.0935

21. Dahan A. Opioid-induced respiratory effects: new data on buprenorphine. Palliat Med 2006;20 Suppl 1:s3-8.

22. Gal TJ. Naloxone reversal of buprenorphine-induced respiratory depression. Clin Pharmacol Ther 1989;45:66-71. https://doi.org/10.1038/clpt.1989.10 